Article

\title{
Functionalized Electrospun Fibers for the Design of Novel Hydrophobic and Anticorrosive Surfaces
}

\author{
Pedro J. Rivero ${ }^{1,2, *}$, David Yurrita ${ }^{1}$, Carlos Berlanga ${ }^{1,2}$, José F. Palacio ${ }^{3}$ and \\ Rafael Rodríguez 1,2 (iD \\ 1 Materials Engineering Laboratory, Department of Engineering, Public University of Navarre, Campus \\ Arrosadía S/N, 31006 Pamplona, Spain; yurrita.78399@e.unavarra.es (D.Y.); \\ carlos.berlanga@unavarra.es (C.B.); rafael.rodriguez@unavarra.es (R.R.) \\ 2 Institute for Advanced Materials (INAMAT), Public University of Navarre. Campus Arrosadía S/N, \\ 31006 Pamplona, Spain \\ 3 Centre of Advanced Surface Engineering, AIN, 31191 Cordovilla, Spain; jfpalacio@ain.es \\ * Correspondence: pedrojose.rivero@unavarra.es
}

Received: 25 July 2018; Accepted: 24 August 2018; Published: 25 August 2018

\begin{abstract}
In this work, a novel coating was deposited on aluminum alloy samples by using a combination of electrospinning and chemical vapor deposition (CVD-silanization) techniques in order to create a functionalized film with an enhancement of both corrosion resistance and hydrophobicity. The electrospinning technique makes the fabrication of highly crosslinked electrospun fibers possible by the combination of both poly(acrylic acid) and $\beta$-cyclodextrin, respectively, which can be easily functionalized in a further step by using the CVD-silanization process due to the evaporation of a hydrophobic molecule such as $1 \mathrm{H}, 1 \mathrm{H}, 2 \mathrm{H}, 2 \mathrm{H}$-Perflurodecyltriethoxysilane. In addition, the resultant electrospun fibers with a high degree of insolubility have been successfully fabricated and metal oxide nanoparticles $\left(\mathrm{TiO}_{2} \mathrm{NPs}\right)$ have been incorporated into the electrospun polymeric solution in order to improve the corrosion protection. The surface morphology has been determined by using light optical microscopy, atomic force microscopy, scanning electron microscopy, and water contact angle (WCA) measurements. The corrosion resistance has been evaluated by using both potentiodynamic polarization and pitting corrosion tests. Finally, the results related to WCA measurements after CVD-silanization corroborate that the surfaces have been successfully functionalized with a hydrophobic behavior in comparison with the electrospinning process, showing a considerable difference in the roughness.
\end{abstract}

Keywords: electrospun fibers; CVD; functionalized surfaces; hydrophobicity; corrosion protection

\section{Introduction}

Aluminum and its alloys are, after steels and cast irons, the most used group of metallic materials due to their combination of properties such as its mechanical strength, high conformability, ductility, light weight and relative low cost. In the case of the 2XXX, 6XXX and 7XXX series, mechanical properties can reach the highest values by means solubilization and ageing processes, which are routine treatments. Due to these intrinsic characteristics, these alloys are choice materials for aeronautical applications [1], although they are employed in many other industrial sectors and common applications. One of the most common alloys is the AA6061, widely used in aeronautics, as well as in shipbuilding or automotive industry. For these specific applications, the corrosion prevention in media such as aqueous solution of chloride ions is a main concern and due to this, multiple works can be found in the bibliography for the design of coatings that provide long-lasting corrosion resistance [2,3]. The use of chromates as corrosion inhibitors has been an ideal alternative for providing the desired protection 
requirements which can be easily implemented by chromate conversion [4,5]. However, the use of hexavalent chromium compounds is being banned in most industrialized countries because they are extremely dangerous for the ecosystem and human health [6,7]. Due to these important drawbacks, the scientific community has been looking for safer and ecofriendly alternatives with the aim to replace these toxic chromium compounds [8].

Among all the alternatives, the sol-gel technology has been one of the most used methodologies to provide corrosion protection [9-13] because silicon alkoxyde precursors show an adequate balance of reactivity and ease of handling combined with a ready availability [14]. However, a novel technique that shows a growing implementation for industrial applications is the electrospinning technique because it is a versatile and flexible process for producing ultrathin fibers from a wide range of materials (polymers, composites, and ceramics) onto any type of surface with arbitrary geometry [15]. This technique uses a high voltage source to inject a charge of a certain polarity into a polymeric solution which is then accelerated toward a collector of opposite polarity. The fiber jet travels through the atmosphere allowing the solvent to evaporate, leading to the deposition of solid polymeric fibers on the collector [16]. It has been demonstrated that a good control over the key processing parameters (mostly voltage, collector distance, flow rate and polymeric viscosity) can greatly influence the final properties for an adequate fiber deposition onto the substrate [17].

In recent years, several works can be found in the bibliography related to the design of electrospun anticorrosion coatings by using different types of polymeric precursors such as polyaniline (PANI) [18,19], polyvinyl alcohol (PVA) [20], poly(vinylidene fluoride) (PVDF) [21] or cellulose acetate (CA) [22]. In addition, other works are focused on the use of electrospun fibers as ideal hosts for corrosion inhibitors such as cerium chloride or lithium carbonate [23], 2-mercaptobenzothiazole (MBT) [24] or inorganic ZnO nanoparticles [25]. It is important to remark that the other additional advantage of the electrospinning process is that the resultant electrospun fibers show a very high surface to volume ratio, making possible the design of coatings for a further chemical or physical functionalization. In this respect, the other works are based on the design of coatings by combining electrospinning and other different deposition techniques such as drop-casting [26], dip-coating [22], or spray-coating [27]. According to this, this work presents a surface functionalized structure based on a novel coating made of crosslinked electrospun fibers combined with inorganic titanium dioxide nanoparticles $\left(\mathrm{TiO}_{2} \mathrm{NPs}\right)$ and a further functionalization by chemical vapor deposition (CVD-silanization) to provide to the previous coating higher hydrophobic properties. To the best of our knowledge, here we present, for the first time, an electrospun coating based on an inner part of $\mathrm{TiO}_{2} \mathrm{NPs}$ and an outer part with a fluorinated tail. The results corroborate that it is possible to achieve the required level of roughness for producing an increase in the resultant water contact angle value thanks to the CVD-silanization process, whereas the presence of $\mathrm{TiO}_{2} \mathrm{NPs}$ into the crosslinked electrospun fibers enables an improvement in the corrosion resistance of the coatings.

\section{Experimental Section}

\subsection{Materials and Reagents}

In this work, the 6061-T6 alloy has been used as a metallic reference substrate for the fabrication of the coatings. Rectangular samples have been prepared with a final dimension of $100 \mathrm{~mm}$ of length, $25 \mathrm{~mm}$ of width and $2.5 \mathrm{~mm}$ of thickness, respectively. All the samples were washed in ethanol, rinsed in distilled water and finally dried in air at room temperature before being used as collectors for the electrospun mats, as it will be explained in the following section.

The polymers poly(acrylic acid), PAA $\left(\mathrm{M}_{\mathrm{w}} \approx 100,000 \mathrm{sol} .35 \mathrm{wt} \%\right.$ in water), $\beta$-cyclodextrin, $\beta-\mathrm{CD}$ (purity 98\%), and $1 \mathrm{H}, 1 \mathrm{H}, 2 \mathrm{H}, 2 \mathrm{H}-$ Perfluorodecyltriethoxysilane (purity 97\%), as well as titanium dioxide nanoparticles $\left(\mathrm{TiO}_{2} \mathrm{NPs}\right)$, were provided from Sigma Aldrich (Saint Louis, MO, USA) and used without any further purification. 


\subsection{Preparation of the Electrospun Solutions}

In this work, three different polymeric solutions have been prepared for the fabrication of the fibrous coatings. The first one consists of PAA ( $35 \mathrm{wt} \%$ in water) which has been directly used for the electrospinning process. The second one is based on the incorporation of a crosslinker agent such as $\beta-C D$ to the PAA solution. The resultant crosslinked PAA fiber mats showed a $16 \%$ of $\beta-C D / P A A$ weight ratio. Finally, the third one is based on the incorporation of a specific corrosion inhibitor such as $\mathrm{TiO}_{2} \mathrm{NPs}$ in the previous crosslinked PAA solution, showing a 10\% weight ratio, respectively. All the obtained solutions were ready for electrospinning after $24 \mathrm{~h}$ under magnetic stirring (Selecta Agimatic, J. P. Selecta, Barcelona, Spain) at room temperature.

\subsection{Construction of the Functionalized Coatings}

In the first stage of coating, freshly prepared solutions were electrospun using a syringe pump (KDS100, KD Scientific, Holliston, MA, USA) at a flow rate of $0.5 \mathrm{~mL} / \mathrm{h}$. The needle (anode) and a plane aluminum sheet (cathode) have been placed at a final distance of $20 \mathrm{~cm}$ from the anode, and a specific voltage of $17 \mathrm{KV}$ has been applied between them. After $2 \mathrm{~h}$, the as-prepared fibers have been dried at $180{ }^{\circ} \mathrm{C}$ for $30 \mathrm{~min}$ in order to remove the residual solvent. A summary of the experimental parameters selected for the deposition of the electrospun fibers is presented in Table 1.

Table 1. The summary of the experimental conditions used for the fabrication of the electrospun fibers.

\begin{tabular}{ccccc}
\hline Molecular Weight (wt \%) & Voltage & Flow Rate & Collector Distance & Thermal Treatment \\
\hline $\mathrm{M}_{\mathrm{w}} \approx 100,000$ & $17 \mathrm{kV}$ & $0.5 \mathrm{~mL} / \mathrm{h}$ & $20 \mathrm{~cm}$ & $180^{\circ} \mathrm{C}$ \\
\hline
\end{tabular}

Additionally, in a second stage, some of the prepared electrospun coatings have been functionalized by CVD-silanization of $1 \mathrm{H}, 1 \mathrm{H}, 2 \mathrm{H}, 2 \mathrm{H}-$ Perfluorodecyltriethoxysilane (97\%) with the main objective of increasing the resultant hydrophobicity [28]. The presence of fluorinated groups in the outer surface is of great interest for creating hydrophobic surfaces because they can satisfy the condition of a low energy of interaction with water, obtaining a strong repellence of the water [29-32]. In order to achieve it, the electrospun fiber coatings have been introduced into a glass flask together with $200 \mu \mathrm{L}$ of $1 \mathrm{H}, 1 \mathrm{H}, 2 \mathrm{H}, 2 \mathrm{H}-\mathrm{Perfluorodecyltriethoxysilane} \mathrm{(97 \% ),} \mathrm{sealing} \mathrm{it} \mathrm{hermetically} \mathrm{[33].} \mathrm{Then,}$ the recipient has been introduced into an oven at a temperature of $150{ }^{\circ} \mathrm{C}$ for a period of time of $150 \mathrm{~min}$ to ease the silane evaporation as well as its reaction with the electrospun nanocoating. Due to the silane nature of the reagent, this process is known as silanization. A scheme of the whole fabrication process divided into two main steps (electrospun fibers and CVD silanization, respectively), which has been used for the fabrication of the coating can be observed in Figure 1.

a) Electrospinning

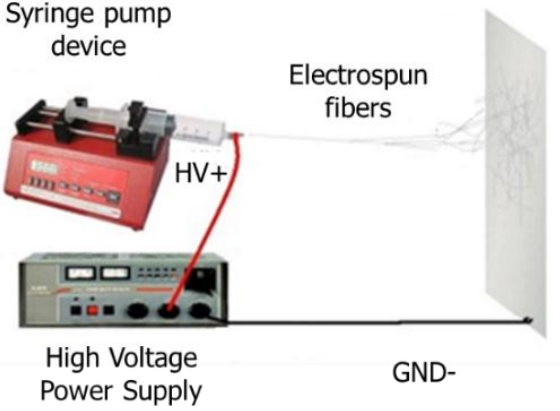

b) CVD - silanization

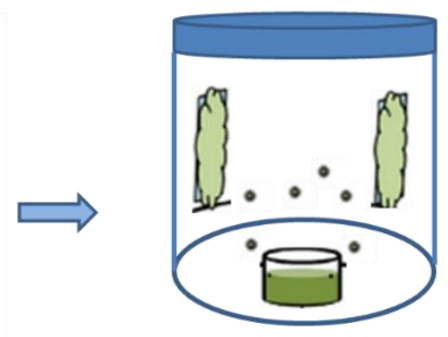

$1 \mathrm{H}, 1 \mathrm{H}, 2 \mathrm{H}, 2 \mathrm{H}-$

Perfluorodecyltriethoxysilane

Figure 1. The scheme of the two different techniques employed in the preparation of the coating from the electrospinning process (a) to CVD-silanization (b). 


\subsection{Fiber Characterization}

The fiber mats were characterized using optical microscopy (Leica DM2500P, Leica Microsystems $\mathrm{GmbH}$, Wetzlar, Germany) and atomic force microscopy (AFM, Innova Veeco, Plainview, NY, USA) in the tapping mode. The electrospun surfaces were also analyzed using Scanning Electron Microscopy (SEM, Hitachi S4800, Tokyo, Japan). The contact angle was registered with a contact angle meter (CAM 100 KSV Instrument, Burlington, VT, USA).

\subsection{Electrochemical Corrosion Tests}

A conventional three-electrode system was used for the corrosion tests composed of a saturated $\mathrm{Ag} / \mathrm{AgCl}$ as the reference electrode, a platinum plate as the counter electrode, and the electrospun coated samples (bare $\mathrm{Al}$ sheet, $\mathrm{PAA}+\beta-\mathrm{CD}$ and $\mathrm{PAA}+\beta-\mathrm{CD}+\mathrm{TiO}_{2} \mathrm{NPs}$ ) after immersion in $3.5 \mathrm{wt}$ $\% \mathrm{NaCl}$ solution and an exposed area of $0.78 \mathrm{~cm}^{2}$ as the working electrode. All the measurements were performed using the Autolab PGSTAT30 galvanostat/potentiostat system (Metrohm, Herisau, Switzerland) at room temperature. A fixed distance between both the reference and working electrode was maintained for all the experiments. Tafel polarization curves were obtained at a potential sweep rate of $1 \mathrm{mV} / \mathrm{s}$, and the corrosion data were obtained through superimposing a straight line along the linear portion of the cathodic and anodic curves.

In addition, cyclic potentiodynamic polarization measurements have been performed in order to determine the localized corrosion susceptibility. The samples were immersed in the saline solution for $1 \mathrm{~h}$ before initiating polarization and after that, the potential scan is started beginning at Ecorr. The scan rate is $0.6 \mathrm{~V} / \mathrm{h}$ in the more noble direction. Once the current density reaches a specific value of $5 \mathrm{~mA} / \mathrm{cm}^{2}$, the scan direction is reversed until the hysteresis loop is closed or well until the corrosion potential is reached.

\section{Results and Discussion}

First of all, the electrospinning technique is a good alternative to fabricate materials with a high surface area due to the possibility of producing thin fibers denoted as electrospun fibers from a wide range of materials. In Figure 2, the electrospun fibers from the needle with the formation of the typical Taylor cone, as well as the aspect of the resultant fibers onto the metallic substrate (6061-T6) with a clear white coloration once the deposition process has been performed, can be observed. In this technique, as the electrostatic attraction between the oppositely charged liquid and collector and the electrostatic repulsions between like charges in the liquid become stronger, the leading edge of the polymeric solution changes from a rounded meniscus to a cone (known as the Taylor cone). In this point, the fiber jet is eventually ejected from the Taylor cone as the electric field strength exceeds the surface tension of the liquid [16].

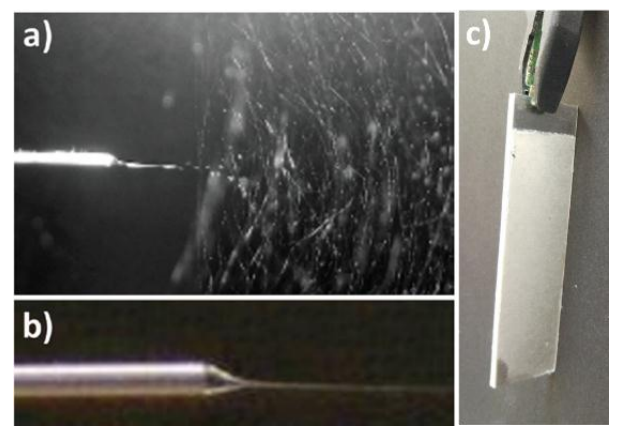

Figure 2. $(\mathbf{a}, \mathbf{b})$ The aspect of the fibers being electrospun towards the cathode from the needle which contains the polymeric solution and a detail of the Taylor cone formed at the tip of the needle; (c) The aspect of the final coating based on the electrospun fibers onto the reference metallic substrate (6061-T6). 
According to the experimental parameters, the first polymeric solution to be electrospun is only PAA ( $35 \mathrm{wt} \%$ in water). As an initial result, it can be corroborated that PAA fibers are successfully electrospun onto the substrate, although in this initial stage, we have observed that these fibers are easily removed after immersion in ultrapure water. Due to this, a crosslinker agent such as $\beta-C D$ has been added to the PAA polymeric solution, making the fabrication of highly crosslinked PAA fiber mats possible. The results indicate that a high degree of insolubility has been observed after immersion in water for a long period of time in comparison with the uncrosslinked fibers (only electrospun PAA). In Figure 3 , the aspect of the electrospun fibers onto glass slides for PAA and PAA $+\beta-C D$ previous and after immersion in ultrapure water is presented.

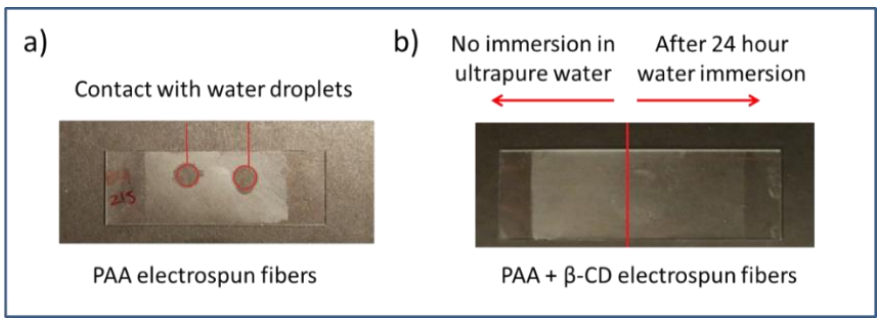

Figure 3. (a) The aspect of the PAA electrospun fibers onto glass slides, showing a total removal of the coating after contact with the water droplets; (b) The aspect of the PAA $+\beta-C D$ electrospun fibers where the coating remains totally unaltered after $24 \mathrm{~h}$ immersion water.

Previous works have demonstrated the positive effect of using $\beta-C D$ as a crosslinker agent after thermal treatment (curing step) because the formation of ester bonds by an esterification process are obtained (corroborated by FTIR spectra) [34]. The $\beta-\mathrm{CD}$ rings have several $\mathrm{OH}$ terminal groups, which can result in being chemically bonded to more than one PAA polymeric chain, acting as crosslinkers. In Figure 4, a scheme of the crosslink reaction of the thermally treated electrospun fibers is presented. This reaction's first step is the dehydration of the carboxylic acid groups of PAA, inducing the formation of glutaric anhydride-like rings which react with the hydroxyl terminal groups of $\beta-C D$, and as a result, the formation of covalent bonds between PAA and $\beta-C D$ is formed. An interesting result of this chemical reaction is the formation of highly crosslinked fiber mats which are randomly distributed along the surface, as it can be appreciated in Figure $4 b, c$, respectively. In addition, the presence of free superficial hydroxyl groups $(\mathrm{OH})$ after the chemical crosslink is of great interest for a further functionalization by CVD-silanization process because a high affinity between these superficial $\mathrm{OH}$ groups and the three ethoxy groups of the fluorosilane molecule (PFAS) is obtained, and as a result, an easy evaporation can be produced with the fluorinated chains oriented in the outer electrospun fibers surface.

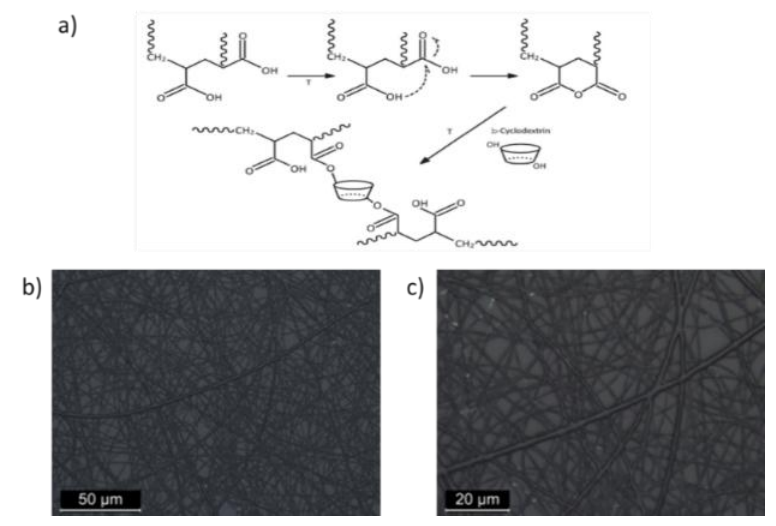

Figure 4. (a) The scheme of the crosslink chemical reaction between PAA and $\beta-C D$ of the thermally treated electrospun fibers; (b) Optical micrograph of the PAA $+\beta-C D$ electrospun fibers (scale $50 \mu \mathrm{m}$ ); and (c) for a scale of $20 \mu \mathrm{m}$. 
Once it the feasibility of the deposition of the electrospun fibers has been demonstrated with a high degree of insolubility after immersion in ultrapure water, the next step was to incorporate a specific corrosion inhibitor such as $\mathrm{TiO}_{2} \mathrm{NPs}$ into PAA + $\beta-\mathrm{CD}$ electrospun fibers. Previous works have demonstrated that this type of metal oxide nanoparticles can be used for improving the anticorrosive properties of the resultant coatings. In addition, $\mathrm{TiO}_{2} \mathrm{NPs}$ show unique properties such as non-toxicity, good compatibility with various materials, high photocatalytic activity, and high ability to absorb ultraviolet light [35-38]. After incorporating these $\mathrm{TiO}_{2} \mathrm{NPs}$ into PAA $+\beta-\mathrm{CD}$ electrospun fibers, no significant differences in the resultant morphology of the surfaces have been observed in the electrospun fibers, showing them in a variable diameter, as it can be appreciated in the SEM images of Figure 5.

a)

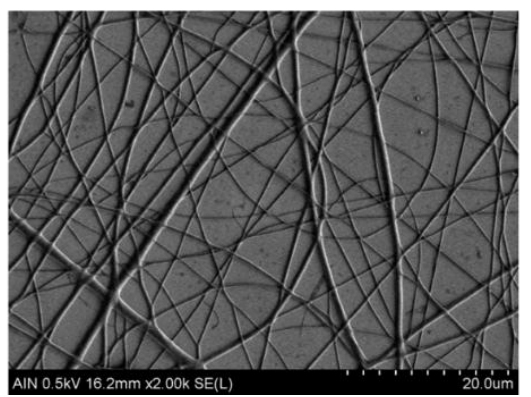

b)

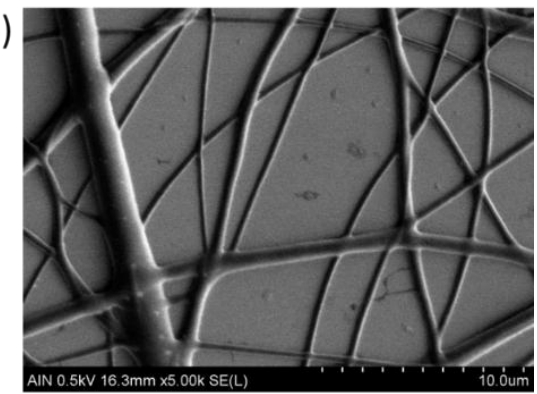

Figure 5. The SEM images of PAA $+\beta-\mathrm{CD}+\mathrm{TiO}_{2} \mathrm{NPs}$ with a scale bar of $20 \mu \mathrm{m}$ (a) and $10 \mu \mathrm{m}$ (b), respectively.

Once the $\mathrm{TiO}_{2} \cdot \mathrm{NPs}$ are incorporated into the electrospun fibers, the next step has been to analyze their corresponding impact in the resultant local corrosion susceptibility (pitting corrosion). Figure 6 shows the cyclic polarization curves for the aluminum bare substrate (6061-T6), the crosslinked electrospun fibers (PAA $+\beta-C D)$, and the crosslinked electrospun fibers with metal oxide nanoparticles $\left(\mathrm{PAA}+\beta-\mathrm{CD}+\mathrm{TiO}_{2} \mathrm{NPs}\right)$.

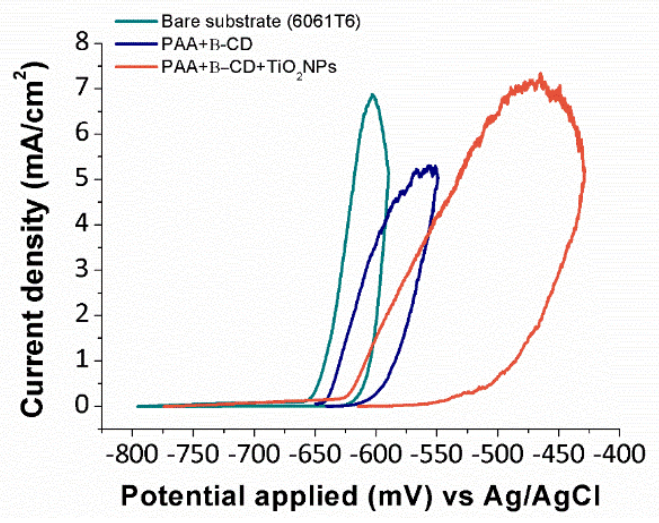

Figure 6. The cyclic polarization curves in $3.5 \% \mathrm{NaCl}$ solution for aluminum bare substrate (black line), crosslinked PAA $+\beta-C D$ electrospun fibers (blue line) and crosslinked electrospun fibers with metal oxide nanoparticles $\left(\mathrm{PAA}+\beta-\mathrm{CD}+\mathrm{TiO}_{2} \cdot \mathrm{NPs}\right.$ ) (orange line), respectively.

First of all, it is important to remark that the best result is observed for the sample with $\mathrm{TiO}_{2} \mathrm{NPs}$ which exhibits the least negative potential $(-532.6 \mathrm{mV})$ in comparison with the bare substrate $(-624.2 \mathrm{mV})$ and crosslinked PAA $+\beta-C D$ electrospun fibers $(-617.2 \mathrm{mV})$. This result clearly indicates that the presence of $\mathrm{TiO}_{2} \mathrm{NPs}$ makes an improvement in the corrosion resistance of the coatings possible. Furthermore, the anti-corrosive behavior has been also evaluated by Tafel polarization curves where an excellent corrosion resistance corresponds to a lower corrosion rate, which can be 
associated to a higher corrosion potential as well as a lower corrosion current density. The experimental results corroborate that the electrospun sample composed of $\mathrm{TiO}_{2} \mathrm{NPs}_{\mathrm{s}}$ show a corrosion rate three times smaller $(0.0043 \mathrm{~mm} /$ year $)$ than the bare aluminum substrate $(0.0138 \mathrm{~mm} /$ year $)$, as it can be appreciated in Table 2.

Table 2. The summary of the corrosion data of the following samples after immersion in $3.5 \mathrm{wt} \% \mathrm{NaCl}$ solution obtained from Tafel polarization measurements.

\begin{tabular}{|c|c|c|c|c|}
\hline Sample & $\begin{array}{c}\text { Corrosion Rate } \\
(\mathrm{mm} / \text { year })\end{array}$ & $\begin{array}{l}\text { Current Density } \\
\left(\mathrm{A} / \mathrm{cm}^{2}\right)\end{array}$ & $\begin{array}{c}\text { Anodic Constant } \\
\text { (V/dec) }\end{array}$ & $\begin{array}{c}\text { Cathodic Constant } \\
\text { (V/dec) }\end{array}$ \\
\hline Aluminum bare (6061T6) & 0.0138 & $6.383 \times 10^{-7}$ & 0.0428 & 0.1440 \\
\hline $\mathrm{PAA}+\beta-\mathrm{CD}$ & 0.0060 & $2.789 \times 10^{-7}$ & 0.0222 & 0.0376 \\
\hline $\mathrm{PAA}+\beta-\mathrm{CD}+\mathrm{TiO}_{2} \mathrm{NPs}$ & 0.0043 & $1.998 \times 10^{-7}$ & 0.0287 & 0.0311 \\
\hline
\end{tabular}

The second aim of this work is to design surfaces with a high degree of hydrophobicity, a chemical evaporation of $1 \mathrm{H}, 1 \mathrm{H}, 2 \mathrm{H}, 2 \mathrm{H}$-Perfluorodecyltriethoxysilane has been performed as it has been previously explained in the Experimental Section. This type of molecule shows a highly hydrophobic part (fluorinated tail), whereas the $\mathrm{Si}-\mathrm{O}$ constitutes the hydrophilic head. After performing CVD-silanization, the hydrophilic head of the molecule is oriented towards the hydrophilic surface of the electrospun fibers and the hydrophobic tail is oriented up to the outer surface, producing a considerable change of the resultant wettability. This aspect is corroborated by the water contact angle (WCA) measurements previous and after the CVD-silanization process, as it can be appreciated in Figure 7. The experimental results indicate that an increase of the WCA value has been obtained from $23.95^{\circ}$ (only electrospun fiber) up to a value of $125.8^{\circ}$ (after the CVD silanization process). This improvement in the WCA value is possibly due to the synergetic effect of the lower free surface energy and the enhanced surface roughness. In this sense, the presence of the fluorinated groups in the outer surface satisfies both conditions, and as a result, water is strongly repelled by these surfaces.

a)

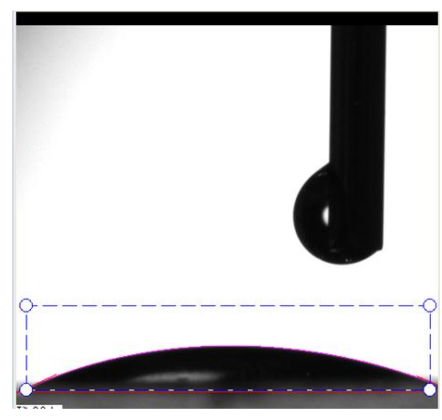

As electrospun fibers b)

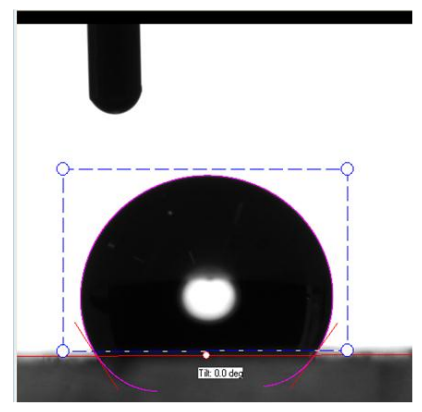

After CVD-silanization

Figure 7. The variation of the water contact angle (WCA): (a) electrospun fibers composed of PAA $+\beta-\mathrm{CD}+\mathrm{TiO}_{2} \mathrm{NPs}$ (hydrophilic behavior with a value of $23.95^{\circ}$ ); (b) electrospun fibers after the CVD-silanization process (hydrophobic behavior with a value of $125.80^{\circ}$ ).

One of these conditions is clearly appreciated in the AFM images presented in Figure 8. The morphology of the coatings was analyzed before and after the CVD-silanization process, and an important change in the resultant morphology was observed because an increase in the surface roughness is obtained after the CVD-silanization process. The roughness (RMS) before silanization (as prepared electrospun fibers, Figure 8b) was $152 \mathrm{~nm}$, whereas the roughness value after the CVD-silanization process (Figure 8d) was $337 \mathrm{~nm}$. For a better appreciation of the topographic distribution of the electrospun coatings after the CVD-silanization process, the SEM images are presented in Figure 9. As it was previously observed in the AFM images, the presence of several valleys 
and hills combined with the electrospun fibers can be clearly observed. In addition, no significant differences in the corrosion behavior of the coating after CVD silanization (similar pitting corrosion potential as well as corrosion rate) has been observed in comparison with the electrospun fibers with $\mathrm{TiO}_{2} \mathrm{NPs}$, preserving the good behavior as anticorrosive surfaces with the novel property of highly hydrophobicity.

a)

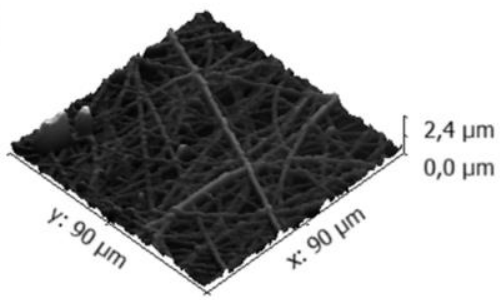

c)

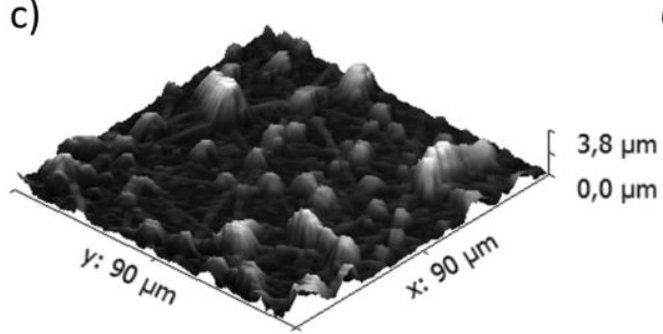

b)

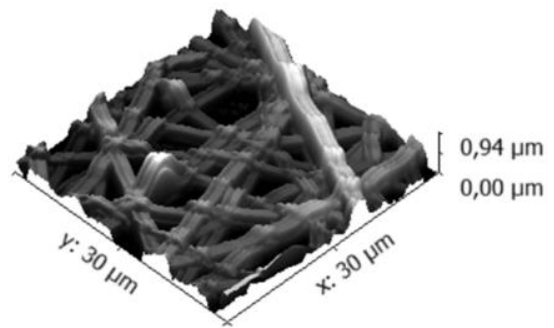

d)

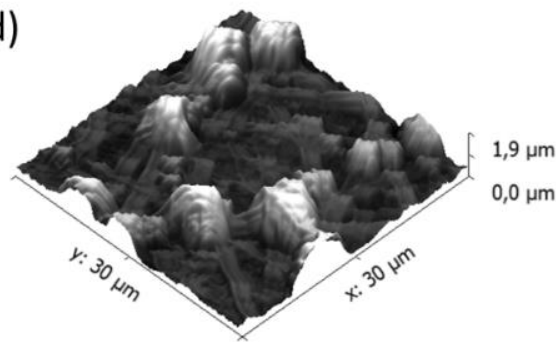

Figure 8. $(\mathbf{a}, \mathbf{b})$ The $3 \mathrm{D}-\mathrm{AFM}$ images of as electrospun fibers of PAA $+\beta-\mathrm{CD}+\mathrm{TiO}_{2} \mathrm{NPs}$ (previous CVD-silanization) for a dimension range of $90 \mu \mathrm{m} \times 90 \mu \mathrm{m}$ and $30 \mu \mathrm{m} \times 30 \mu \mathrm{m}$, respectively; (c,d) 3D-AFM images after the CVD-silanization process of the electrospun fibers for a dimension range of $90 \mu \mathrm{m} \times 90 \mu \mathrm{m}$ and $30 \mu \mathrm{m} \times 30 \mu \mathrm{m}$, respectively.

a)

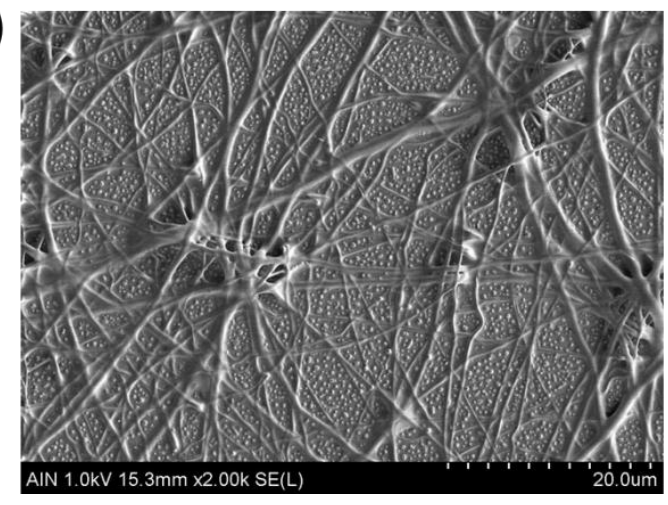

b)

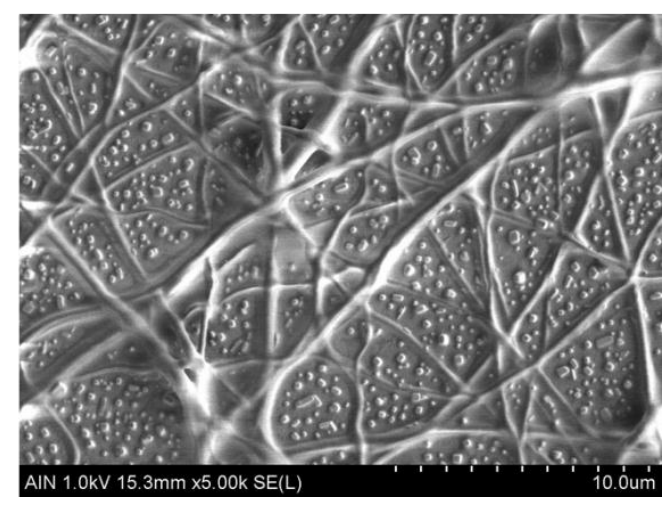

Figure 9. SEM images of the electrospun fibers after the CVD-silanization process for a scale bar of (a) $20 \mu \mathrm{m}$ and (b) $10 \mu \mathrm{m}$, respectively.

To sum up, this is the first time that a combination of a dual deposition process of both the electrospinning technique and the CVD-silanization process is presented in the bibliography. All the results corroborate that the resultant functionalized coatings showed a great behavior as an anticorrosive coating with a high degree of hydrophobicity, thus, being a good alternative in its implementation in industrial applications. 


\section{Conclusions}

In this work, a novel coating which combines two different deposition technologies is presented for the design of functionalized surfaces. In a first step, crosslinked electrospun fibers with $\mathrm{TiO}_{2} \mathrm{NPs}$ (denoted as PAA $+\beta-\mathrm{CD}+\mathrm{TiO}_{2} \mathrm{NPs}$ ) were successfully deposited onto 6061-T6 substrates, showing a high degree of insolubility after log immersion in ultrapure water. In addition, the resultant coatings present a more positive pitting potential $(-532.6 \mathrm{mV})$ than the bare aluminum substrate $(-624.2 \mathrm{mV})$, whereas the corrosion rate was three times smaller $(0.0043 \mathrm{~mm} /$ year $)$ than the bare aluminum substrate $(0.0138 \mathrm{~mm} /$ year). Then, in a second step, the prepared electrospun coatings were functionalized by CVD-silanization of $1 \mathrm{H}, 1 \mathrm{H}, 2 \mathrm{H}, 2 \mathrm{H}$-Perfluorodecyltriethoxysilane with the aim to obtain a change in the surface roughness which produces a low energy of interaction with water. The results corroborate that after CVD, the roughness (RMS) value has been changed from $152 \mathrm{~nm}$ up to $337 \mathrm{~nm}$, whereas the resultant water contact angle (WCA) value has varied from $23.95^{\circ}$ up to $125.80^{\circ}$, showing a considerable increase in the hydrophobicity of the electrospun fibers.

Author Contributions: Conceptualization, P.J.R., C.B and D.Y.; Methodology, P.J.R. and D.Y.; Validation, P.J.R., D.Y. and R.R.; Formal Analysis, P.J.R., C.B and J.F.P.; Investigation, P.J.R., D.Y., J.F.P. and R.R.; Writing-Original Draft Preparation, P.J.R. and D.Y.; Writing-Review \& Editing, P.J.R. and D.Y.; Supervision, P.J.R., C.B. and R.R.

Funding: This work was funded by the Spanish Economy and Competitiveness Ministry-FEDER Proyecto Retos (TRA2013-48603-C4-1-R) and the Public University (Navarre-PRO-UPNA18 (6107)).

Acknowledgments: The authors would like to express their gratitude to Nadetech Inc. for the design, fabrication and tune-up of the robot for the deposition of the electrospun fibers.

Conflicts of Interest: The authors declare that they have no competing interests.

\section{References}

1. Immarigeon, J.-P.; Holt, R.T.; Koul, A.K.; Zhao, L.; Wallace, W.; Beddoes, J.C. Lightweight materials for aircraft applications. Mater. Charact. 1995, 35, 41-67. [CrossRef]

2. Guillaumin, V.; Mankowski, G. Localized corrosion of 2024 T351 aluminium alloy in chloride media. Corros. Sci. 1998, 41, 421-438. [CrossRef]

3. Szklarska-Smialowska, Z. Pitting corrosion of aluminum. Corros. Sci. 1999, 41, 1743-1767. [CrossRef]

4. Kendig, M.; Jeanjaquet, S.; Addison, R.; Waldrop, J. Role of hexavalent chromium in the inhibition of corrosion of aluminum alloys. Surf. Coat. Technol. 2001, 140, 58-66. [CrossRef]

5. Kimbrough, D.E.; Cohen, Y.; Winer, A.M.; Creelman, L.; Mabuni, C. A critical assessment of chromium in the environment. Crit. Rev. Environ. Sci. Technol. 1999, 29, 1-46. [CrossRef]

6. Costa, M.; Klein, C.B. Toxicity and carcinogenicity of chromium compounds in humans. Crit. Rev. Toxicol. 2006, 36, 155-163. [CrossRef] [PubMed]

7. Kulinich, S.A.; Akhtar, A.S. On conversion coating treatments to replace chromating for Al alloys: Recent developments and possible future directions. Russ. J. Non-Ferrous Met. 2012, 53, 176-203. [CrossRef]

8. Twite, R.L.; Bierwagen, G.P. Review of alternatives to chromate for corrosion protection of aluminum aerospace alloys. Prog. Org. Coat. 1998, 33, 91-100. [CrossRef]

9. Wang, D.; Bierwagen, G.P. Sol-gel coatings on metals for corrosion protection. Prog. Org. Coat. 2009, 64, 327-338. [CrossRef]

10. Collinson, M.M.; Wang, H.; Makote, R.; Khramov, A. The effects of drying time and relative humidity on the stability of sol-gel derived silicate films in solution. J. Electroanal. Chem. 2002, 519, 65-71. [CrossRef]

11. Lamaka, S.V.; Montemor, M.F.; Galio, A.F.; Zheludkevich, M.L.; Trindade, C.; Dick, L.F.; Ferreira, M.G.S. Novel hybrid sol-gel coatings for corrosion protection of AZ31B magnesium alloy. Electrochim. Acta 2008, 53, 4773-4783. [CrossRef]

12. Vasconcelos, D.C.L.; Carvalho, J.A.N.; Mantel, M.; Vasconcelos, W.L. Corrosion resistance of stainless steel coated with sol-gel silica. J. Non-Cryst. Solids 2000, 273, 135-139. [CrossRef]

13. Altube, A.; García-Lecina, E.; Imaz, N.; Díez, J.A.; Ferrón, P.; Aizpurua, J.M. Influence of deposition conditions on the protective behavior of tetraethyl orthosilicate sol-gel films on AA5754 aluminum alloy. Prog. Org. Coat. 2012, 74, 281-287. [CrossRef] 
14. Brinker, C.J.; Scherer, G.W. Sol-Gel Science: The Physics and Chemistry of Sol-Gel Processing, 1st ed.; Academic Press: Cambridge, MA, USA, 2013.

15. Li, D.; Xia, Y. Electrospinning of nanofibers: reinventing the wheel? Adv. Mater. 2004, 16, 1151-1170. [CrossRef]

16. Sill, T.J.; von Recum, H.A. Electrospinning: Applications in drug delivery and tissue engineering. Biomaterials 2008, 29, 1989-2006. [CrossRef] [PubMed]

17. Firouzi, A.; Impagnatiello, A.; Del Gaudio, C.; Lamastra, F.R.; Bianco, A.; Montesperelli, G. Electrospun protective self-healing coatings for light alloys: A better understanding of the intrinsic potential of the technology. J. Appl. Polym. Sci. 2015, 132, 42728. [CrossRef]

18. Zhao, Y.; Zhang, Z.; Yu, L. Corrosion protection of carbon steel by electrospun film containing polyaniline microfibers. React. Funct. Polym. 2016, 102, 20-26. [CrossRef]

19. Zhao, Y.; Zhang, Z.; Yu, L.; Tang, Q. Electrospinning of polyaniline microfibers for anticorrosion coatings: An avenue of enhancing anticorrosion behaviors. Synth. Met. 2016, 212, 84-90. [CrossRef]

20. Firouzi, A.; Del Gaudio, C.; Lamastra, F.R.; Montesperelli, G.; Bianco, A. Electrospun polymeric coatings on aluminum alloy as a straightforward approach for corrosion protection. J. Appl. Polym. Sci. 2015, 132, 41250. [CrossRef]

21. Cui, M.; Xu, C.; Shen, Y.; Tian, H.; Feng, H.; Li, J. Electrospinning superhydrophobic nanofibrous poly(vinylidene fluoride)/stearic acid coatings with excellent corrosion resistance. Thin Solid Films 2018, 657, 88-94. [CrossRef]

22. Zhong, Z.; Qin, J.; Ma, J. Cellulose acetate/hydroxyapatite/chitosan coatings for improved corrosion resistance and bioactivity. Mater. Sci. Eng. C 2015, 49, 251-255. [CrossRef] [PubMed]

23. Dieleman, C.D.; Denissen, P.J.; Garcia, S.J. Long-term active corrosion protection of damaged coated-AA2024-T3 by embedded electrospun inhibiting nanonetworks. Adv. Mater. Interfaces 2018, 5, 1800176. [CrossRef]

24. Dong, Y.; Li, S.; Zhou, Q. Self-healing capability of inhibitor-encapsulating polyvinyl alcohol/polyvinylidene fluoride coaxial nanofibers loaded in epoxy resin coatings. Prog. Org. Coat. 2018, 120, 49-57. [CrossRef]

25. Radwan, A.B.; Mohamed, A.M.A.; Abdullah, A.M.; Al-Maadeed, M.A. Corrosion protection of electrospun PVDF-ZnO superhydrophobic coating. Surf. Coat. Technol. 2016, 289, 136-143. [CrossRef]

26. Zhao, Y.; Xing, C.; Zhang, Z.; Yu, L. Superhydrophobic polyaniline/polystyrene micro/nanostructures as anticorrosion coatings. React Funct. Polym. 2017, 119, 95-104. [CrossRef]

27. Zhao, Y.; Zhang, Z.; Yu, L.; Jiang, T. Hydrophobic polystyrene/electro-spun polyaniline coatings for corrosion protection. Synth. Met. 2017, 234, 166-174. [CrossRef]

28. Bravo, J.; Zhai, L.; Wu, Z.; Cohen, R.E.; Rubner, M.F. Transparent superhydrophobic films based on silica nanoparticles. Langmuir 2007, 23, 7293-7298. [CrossRef] [PubMed]

29. Yu, Q.; Xu, J. Structure and surface properties of fluorinated organic-inorganic hybrid films. J. Sol-Gel Sci. Technol. 2012, 61, 243-248. [CrossRef]

30. Maeztu, J.D.; Rivero, P.J.; Berlanga, C.; Bastidas, D.M.; Palacio, J.F.; Rodriguez, R. Effect of graphene oxide and fluorinated polymeric chains incorporated in a multilayered sol-gel nanocoating for the design of corrosion resistant and hydrophobic surfaces. Appl. Surf. Sci. 2017, 419, 138-149. [CrossRef]

31. Wankhede, R.G.; Morey, S.; Khanna, A.S.; Birbilis, N. Development of water-repellent organic-inorganic hybrid sol-gel coatings on aluminum using short chain perfluoro polymer emulsion. Appl. Surf. Sci. 2013, 283, 1051-1059. [CrossRef]

32. Jeong, H.-J.; Kim, D.-K.; Lee, S.-B.; Kwon, S.-H.; Kadono, K. Preparation of water-repellent glass by sol-gel process using perfluoroalkylsilane and tetraethoxysilane. J. Colloid Interface Sci. 2001, 235, 130-134. [CrossRef] [PubMed]

33. Lopez-Torres, D.; Elosua, C.; Hernaez, M.; Goicoechea, J.; Arregui, F.J. From superhydrophilic to superhydrophobic surfaces by means of polymeric layer-by-layer films. Appl. Surf. Sci. 2015, 351, 1081-1086. [CrossRef]

34. Rivero, P.J.; Urrutia, A.; Goicoechea, J.; Rodríguez, Y.; Corres, J.M.; Arregui, F.J.; Matías, I.R. An antibacterial submicron fiber mat with in situ synthesized silver nanoparticles. J. Appl. Polym. Sci. 2012, 126, 1228-1235. [CrossRef] 
35. Zaharescu, M.; Predoana, L.; Barau, A.; Raps, D.; Gammel, F.; Rosero-Navarro, N.C.; Castro, Y.; Durán, A.; Aparicio, $\mathrm{M}$. $\mathrm{SiO}_{2}$ based hybrid inorganic-organic films doped with $\mathrm{TiO}_{2}-\mathrm{CeO}_{2}$ nanoparticles for corrosion protection of AA2024 and mg-AZ31B alloys. Corros. Sci. 2009, 51, 1998-2005. [CrossRef]

36. Radoman, T.S.; Džunuzovic, J.V.; Jeremic, K.B.; Grgur, B.N.; Milicevic, D.S.; Popovic, I.G.; Džunuzovic, E.S. Improvement of epoxy resin properties by incorporation of $\mathrm{TiO}_{2}$ nanoparticles surface modified with gallic acid esters. Mater. Des. 2014, 62, 158-167. [CrossRef]

37. Balaskas, A.C.; Kartsonakis, I.A.; Tziveleka, L.-A.; Kordas, G.C. Improvement of anti-corrosive properties of epoxy-coated AA 2024-T3 with $\mathrm{TiO}_{2}$ nanocontainers loaded with 8-hydroxyquinoline. Prog. Org. Coat. 2012, 74, 418-426. [CrossRef]

38. Zhang, X.; Wang, F.; Du, Y. Effect of nano-sized titanium powder addition on corrosion performance of epoxy coatings. Surf. Coat. Technol. 2007, 201, 7241-7245. [CrossRef]

2018 by the authors. Licensee MDPI, Basel, Switzerland. This article is an open access article distributed under the terms and conditions of the Creative Commons Attribution (CC BY) license (http://creativecommons.org/licenses/by/4.0/). 